\title{
The Sharing Economy: User - Generated Rating and the Quality of Service in Tourism
}

\author{
Greicy K Silva \\ Faculty of Sciences \\ \& Technology (UNL) \\ Lisbon, 2267057, Portugal \\ greicy.silva@m-iti.org
}

\author{
Claudia Silva \\ Madeira Interactive \\ Technologies Institute \\ Funchal, 2267057, Portugal \\ claudia.silva@m-iti.org
}

\author{
Fernanda Llussá \\ New University of Lisbon \\ Lisbon, 2267057, Portugal \\ fajl@fct.unl.pt
}

\begin{abstract}
The impact of the sharing economy business model continues to grow at a remarkable rate in many sectors. Consumers need to deal with independent service providers (e.g., Airbnb) and not commercial businesses (e.g., hotel chains). We are exploring scientific facts about product quality based on user-generated ratings. We compared Airbnb place ratings with TripAdvisor and analysed why these ratings in the sharing economy platform are so high. Our analysis showed more than 285 properties holding an average user-generated rating score of 5 stars. This directed us to analyse where the review platforms generate doubtful distributions of star ratings, which are questionable reflections of true service quality. In addition, we found considerable variability in ratings. This discrepancy made us question how these distributions occur in the sharing economy, particularly in home-sharing tourism, where rating variability is small compared to that in the traditional hotel industry.
\end{abstract}

\section{Sharing economy. Tourism. User-generated rating. Home-sharing.}

\section{INTRODUCTION}

The phenomenon sharing economy is an umbrella term to describe digital economic systems, and it gives a name to a general trend that is disrupting conventional business models in every sector of the economy. This new economic model, enabled by information and communications technologies (ICTs), has given rise to significantly reduced transaction costs, making it possible for everyone to turn their personal goods, resources, and labour into assets they can sell, share, swap, borrow, or rent.

This scenario made us question the impact of Airbnb in rather small tourist destinations such as islands. Not much research has been conducted in such contexts [8].

With this research need in mind, this paper analyses the impact of Airbnb, as a sharing economy platform, in a medium-sized European tourist Island with 270,000 inhabitants and receiving more than 1.2 million tourists every year with an overnight spending surpassing 6.6 billion (25\% of GDP of the Island generated). We will study Airbnb's usergenerated rating using a dataset we collected, containing all reviews and ratings that are publicly available on the Airbnb online company and compare to an auxiliary data source that we will also gather from publicly available sources on the TripAdvisor web page.

This paper also highlights the relevance of this work for media markets and the media and communication research community related to how the media influences the society. There are times where the mediatisation of companies is shaping and framing the processes and the discourse of society [10]. Home-sharing companies are using the mediatisation of reputation and trust to influence customer's decisions, and through this generating communication power related to the growth of Airbnb, especially, and the sharing economy more broadly.

The online reputation system, using a star rating based on reviews, is a significant driver of consumer behaviour, encouraging consumers to compare and to evaluate products and services. Empirical studies have been analysing star ratings using J-shaped distribution and finding similar conclusions: star ratings tend to be extreme positive, rarely displayed, with a short number of highly negative reviews [5].

While it draws on the current scenario of continuous change and disruption this work is concerned specifically with user rating systems in the homesharing service. In our analysis, we are using independent variables collected from the sharing economy platform Airbnb and comparing them with 
traditional hotel reviews in the platform, TripAdvisor. Considering properties by type, we seek to analyse the similarities between Airbnb and TripAdvisor user ratings. We compare the datasets from both platforms' services, seeking to find any correlation between the samples. In the following section, we refer to each accommodation as 'property' for both platforms regardless of whether it is a 'room' or a 'hotel.' For conducting this analysis, we are relating the best service quality to a maximum number of star ratings.

The sections of this work began with a review of the related work, from which a definition of the sharing economy was formed. Initial views on trust and reputation systems used a user-generated rating. It followed with section 3 breaking down the methodology, with 3.1 goals of the study, 3.2 the data collection, and 3.3 sections with the Airbnb and TripAdvisor dataset distribution with some empirical evidence. After that, section 4 shows the statically results from the tests we conducted. Concluding in section 5, we presented the conclusion and discussion of the finds subsequent with some limitations and the future research that we look forward to exploring.

\section{LITERATURE REVIEW}

The sharing economy can be situated in the struggles and achievements of the ongoing process of technological innovations in the 21st century. Disruption, a consequence of this process, is now in every business sector-even travel, commercial real estate, and transportation [12]. In a nutshell, this disruption is mainly caused by digital technologies, and thus as Arun Sandararajan (2016) has argued that companies need to change their mentality and understand even if they have a physical business it can be digitized [1]. There are several challenges associated with this paradigm shift. One of them is related to trust building because it brings up issues such as risk, discrimination, and accountability for individuals as well as for companies. This alteration will require changes in regulations and different organizational mind-sets [3]. The disruption is so prevalent, that in the sector of tourism, platforms like Airbnb are surpassing traditional global hotel chains in making an impact in the industry.

The new digital economy promises to increase environmental sustainability "by shifting the paradigm away from individual ownership to collectivity and sharing, less demand for consumer goods may give way to a new economy that could help take on problems such as pollution and excessive energy usage [9]." In times of nonownership, other forms of sustainable consumption are given more importance [13]. In relation to this, the sharing economy's expected capacity is to bring an economic reorganization contribution, a shift toward widespread sustainable business practices [4].

\subsection{The research study constructs}

The primary aim of this study is to compare ratings between Airbnb and TripAdvisor with the purpose of understanding, what is the perception of subjective quality in both platforms subjective. Our research question is: can we find significant differences between user-generated ratings in sharing economy services (such as Airbnb) and reviewing platforms (such as TripAdvisor)?

We use Airbnb as a case study to find evidence that will enable us to know how star-ratings distributions occur in the researched phenomena, namely sharing economy in the tourism sector. To make this as logical and unambiguous as possible, we intend to entail evidence to precisely describe and assess meaning in home-sharing practices and observing the user-generated ratings, particularly on Madeira Island. We are seeking to explore scientific facts about product quality based on user-generated ratings and to figure out just how different the ratings from Airbnb and Trip Advisor are. As we are using a random variable based on a small island with 270,000 habitats we hypothesize two things: 1 ) that the variability of prices in Airbnb Madeira is significant than on TripAdvisor and 2) that the variability of star-ratings in Airbnb is small compared to TripAdvisor.

\subsection{Data collection}

Our case study uses data collected directly from Airbnb and TripAdvisor platforms from Madeira Island. We collected the data available online from both digital platforms in October 2016. For Airbnb, this accounted for over 570 properties listed on the Island. As the home-sharing platform does not provide exact locations, we collected the approximate location, the property id, the number of reviews, and the current star rating. As Airbnb does not display star rating with fewer than three reviews in a property page, we only included those with three or more stars in this study, and we discarded any others. The review platform Trip Advisor lists over 1500 local properties, private accommodation business but to be consistent with our results from Airbnb we used only those properties with three or more reviews which left us with 221 Bed\& Breakfast, and hotels.

The first procedure approached a heuristic process to perform matching, as neither platforms had a unique property identifier, we selected properties inside the most touristic areas of the island by parish freguesias for both of the digital platforms. Airbnb often Listed B\&Bs with a collection of rooms, each one with its page, on TripAdvisor we visualized that for every hotel, or 'B\&B,' it could be more than one 
Airbnb property each parish. Also, by eliminating properties with fewer than three reviews, our sample contained only 221 properties listed on TripAdvisor, being that 149 hotels and $72 \mathrm{~B} \& \mathrm{~B}$, compared to 401 properties from Airbnb.

To evaluate the quality of our matches we manually checked the properties pages to avoid erroneous association, but in fact, it was a limitation we faced, and we are looking forward to further improving this issue.

\subsection{Our datasets}

We start displaying the Airbnb distribution and with some empirical evidence noted. Figure 1 shows the Airbnb distribution of properties in Madeira by star rating. Alike [11] we found the start ratings tremendously positive; also, by coincidence or not the distribution Mean seems different. It is counting with $52.4 \%$ of Airbnb properties in the Island rated 5 stars. The largest review platform shows us in Figure 1 the distributions of all hotels and B\&B we found on the Island, using the same methodology as the Airbnb start rating.

TripAdvisor star rating shows in Figure 1 that $15.2 \%$ of properties have the maximum of 5 stars, and $31.3 \%$ are rated 4.5 evidently less overwhelming positive than Airbnb properties. In Table 1 we can visualize this difference in the two distributions reflected in the means, with 4.7 stars for Airbnb and 4.1 stars for TripAdvisor. We conducted more tests and decided to ignore reviews equal to 5 and larger, yet we cannot see the similarity in distributions shown in Table 1 and Table 2. Still, the two tests display a considerable difference in the distribution of Means in both companies. The variability of prices on Airbnb in Madeira is not confirmed as Table 2 shows because the prices are different in both companies' services. The extreme differences founded is the correlation between platforms price fixed for the maximum and the minimum when comparing both companies, see section 4.1. The tests confirmed the second hypothesis in section 4.2, star rating variability on Airbnb is small compared to TripAdvisor that shows no statistical significance.

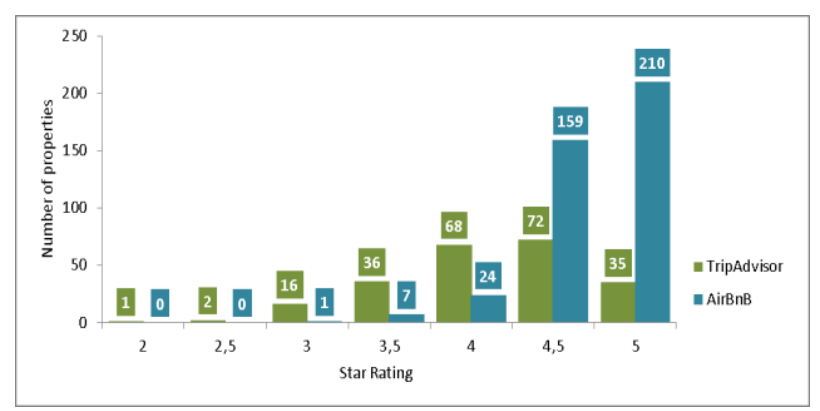

Figure 1: The distribution of ratings for Airbnb and TripAdvisor properties by reviews

\subsection{Statistical method}

To be able to compare both platforms we started to verify the similarities between the star rating system. The method conducted was based on the criteria we established (equal number of star ratings) to be more consistent. To compare these two different groups, we use T-Student test. To measure the homogeneity of variances for Airbnb and TripAdvisor, we used the Levene's test. To verify the correlation between both services we used the test Pearson to determine the statistical significance between the Means of both platform services in this regard we specified the significance alpha level of 0.05 .

\section{COMPARING PROPERTIES ON BOTH COMPANIES}

We use property heterogeneity across Airbnb and TripAdvisor the use of cross-listed properties allows us to control differences in ratings. To better understanding the platform differences, we use the statistical method described in section 3.4. We run as follows a correlation and comparison test between the variables price and rating and the variable rating and number of reviews.

\subsection{Rate comparison}

The rate between TripAdvisor and Airbnb shows differences ( $p$-value $<0.001)$. The TripAdvisor rate is lower than Airbnb rate.

Table 1: T-Student Test: $p$-value $<0.001$

\begin{tabular}{|c|c|c|c|}
\hline Platform & Count & Mean & Std. Deviation \\
\hline TripAdvisor & 221 & 4.1 & 0.6 \\
\hline Airbnb & 401 & 4.7 & 0.4 \\
\hline
\end{tabular}

\subsection{Price comparison}

The price between TripAdvisor and Airbnb shows differences ( $p$-value $<0.001)$. The TripAdvisor price is higher than Airbnb price.

Table 2: T-Student Test: $p$-value $<0.001$

\begin{tabular}{|c|c|c|c|}
\hline Platform & Count & Mean & Std. Deviation \\
\hline TripAdvisor & 134 & 87.6 & 83.7 \\
\hline Airbnb & 576 & 6.5 & 50.7 \\
\hline
\end{tabular}

\subsection{Correlation between rate and price}

\subsubsection{TripAdvisor}

The correlation between rate and price is positive and regular ( $p$-value $<0.001 ; r=0.4$ ). The price and rate vary in the same direction. For example, if the rate increases the price will have the same variation. 


\subsubsection{Airbnb}

The correlation between rate and price is positive and weak ( $p$-value $<0.001 ; r=0.1$ ). The price and rate vary in the same direction. For example, if the rate increases the price will have the same variation.

\subsection{Correlation between rate and number of reviews}

\subsubsection{TripAdvisor}

The correlation between rate and number of reviews shows no statistical significance ( $p$-value $>0.05$ ).

\subsubsection{Airbnb}

The correlation between rate and number of reviews is positive and weak ( $p$-value $<0.05 ; r=0.1$ ). The rate and the number of reviews vary in the same direction. For example, if the rate increases the number of reviews will have the same variation.

\section{DISCUSSION AND GENERALIZATIONS}

This work aimed to provide early insights into an emerging digital sharing economy business model, Airbnb, into user-generated ratings concerning service quality by identifying and comparing with the TripAdvisor platform. The first one is considered by itself as part of the sharing economy, and the second one is described as a travel content website. We questioned if there were differences between the two platforms concerning user-generated ratings. For that, we considered star ratings as decisionmakers for tourists looking for a place to stay, and we assumed that a 5-star rating with 10 reviews was better than fewer reviews. We did not know the customers' particular reasons when they chose one or another, but we selected comparable ratings on vacation rental properties on TripAdvisor. When we looked for rated properties on both platforms, we faced different criteria in the ways the star rating was generated.

In conclusion, home-sharing in tourism is evolving in part in response to changes in tourist behaviour. In general, tourists prefer to be self-guided and look at the information provided by other tourists. The work from Nosko and Tadelis (2014) shows that eBay buyers behave according to their experiences with specific sellers and that buyers who have a poor experience with any one seller are less likely to return to eBay [8]. This new way of consuming online has its precedents, and customers have been exposed to these kinds of experiences before, as that business is still using traditional models and it should be aware of the implications of today's digital consumer behaviour [2].

As noted in this study and at Zervas and Byers study [11], the ratings are usually positive to a considerable level. It leads us to question whether or not tourists truly trust the sharing economy star rating system as a decision parameter. At the platform level, Airbnb generates considerable earnings for hosts as well as for the sharing economy company [14], and there is concern over the fact that star ratings can be displayed on an Airbnb property page after three reviews (see more How Do Star Ratings Work). That generates doubts about trust in online reputations, as customizing the property profile or even starting a new one from scratch is easy to do, thereby avoiding negative reviews and lower ratings. Alternatively, perhaps hosts in the home-sharing industry are delivering a greater experience for tourists on Madeira Island than the traditional local hotels are. The findings reflect the digital disruption by today's sharing economy platforms where consumers have to deal with independent service providers and not traditional hotel chains (in our study example). Ratings may not accurately reflect the quality of service since ratings are important to an Airbnb host and may be managed through communication requesting users to rate them well.

\subsection{Limitations and future research}

There are a few limitations concerning data extraction, first related to the precise location, as it is not available or accessible from the Airbnb platform. For a sharing business model, at least, researchers should have a viable way to access the company's API (Application Programming Interface). Also, as the star rating is pre-set by the platform, it generates an unbiased analysis. According to $\mathrm{Li}$ and Hitt (2007), on the other hand, self-selection bias, if not corrected, decreases consumer surplus [7].

Airbnb's reputation system made our analysis difficult because only properties with three or more reviews display star ratings. The rating criteria on both platforms are different, thereby limiting the analysis of service quality because if a property is not well reviewed on Airbnb, the decision to rent is not up to the customer; it is an algorithm decision.

Our study represents an empirical first step to understanding the complex set of issues involving in the sharing economy. Accumulating evidence of the dynamics and challenges of user ratings, especially from the early days of the sharing economy platforms, is valuable for envisioning how online reputation and trust systems could function better in the future. Another interesting question to be explored further is why the ratings in the sharing economy platforms are so high. Our plan is to conduct structured qualitative interviews to understand this phenomenon.

\section{ACKNOWLEDGEMENTS}

Acknowledgments to Regional Agency for the Development of Research Technology and Innovation through the support granted under the 
M14-20 Project - 09-5369-FSE-000001- PhD Scholarship.

\section{REFERENCES}

1. Copyright (c) Massachusetts Institute of Arun Sandararajan and 1977-2017 All rights. 2016. Crowd-Based Capitalism? Empowering Entrepreneurs in the Sharing Economy. MIT Sloan Management Review. Retrieved April 13, 2017 from http://sloanreview.mit.edu/article/crowd-basedcapitalism-empowering-entrepreneurs-in-thesharing-economy/.

2. Russell Belk. 2014. You are what you can access: Sharing and collaborative consumption online. Journal of Business Research 67, 8: 1595-1600.

3. Rachel Botsman. 2015. The Changing Rules of Trust in the Digital Age. Harvard Business Review. Retrieved March 29, 2017 from https://hbr.org/2015/10/the-changing-rules-oftrust-in-the-digital-age.

4. Boyd Cohen and Jan Kietzmann. 2014. Ride On! Mobility Business Models for the Sharing Economy. Organization \& Environment 27, 3: 279-296.

5. Nan Hu, Jie Zhang, and Paul A. Pavlou. 2009. Overcoming the $\mathrm{J}$-shaped Distribution of Product Reviews. Commun. ACM 52, 10: 144-147.

6. hughrileyblog. 2016. The Sharing Economy \& Its Impact on Caribbean Tourism. Hugh Riley. Retrieved August 6, 2017 from https://hughriley.org/2016/09/26/the-sharingeconomy-its-impact-on-caribbean-tourism/.

7. Xinxin Li and Lorin M. Hitt. 2007. Self Selection and Information Role of Online Product Reviews. Social Science Research Network, Rochester, NY.

8.Chris Nosko and Steven Tadelis. 2015. The Limits of Reputation in Platform Markets: An Empirical Analysis and Field Experiment. Social Science Research Network, Rochester, NY.

9.Andrea Prothero, Susan Dobscha, Jim Freund, et al. 2011. Sustainable Consumption: Opportunities for Consumer Research and Public Policy. Social Science Research Network, Rochester, NY.

10.Igor Savič. 2016. Mediatization of companies as a factor of their communication power and the new role of public relations. Public Relations Review 42, 4: 607-615.

11.Georgios Zervas, Davide Proserpio, and John Byers. 2015. A First Look at Online Reputation on Airbnb, Where Every Stay is Above Average. Social Science Research Network, Rochester, NY.
12.Disruptive Innovation. Clayton Christensen. 2012. Retrieved April 22, 2017 from http://www.claytonchristensen.com/key-concepts/.

13.Collaborative consumption: Determinants of satisfaction and the likelihood of using a sharing economy option again. ResearchGate. Retrieved May 27, 2017 from https://www.researchgate.net/publication/2728905 05_Collaborative_consumption_Determinants_of _satisfaction_and_the_likelihood_of_using_a_sha ring_economy_option_again.

14.Airbnb vs Rent: City of Los Angeles - Inside Airbnb. Adding data to the debate. Inside Airbnb. Retrieved August 7, 2017 from http://insideairbnb.com/airbnb-vs-rent-city-of-la/. 